\title{
Policía y gitanos españoles en la encrucijada democrática: una aproximación desde la documentación del Archivo General del Ministerio del Interior *1
}

\author{
Police and Roma Community in Spain at democratic crossroads: An \\ approach from the Ministry of Interior Historical Archives
}

\author{
Carolina García-Sanz \\ Universidad de Sevilla
}

\section{RESUMEN}

La consolidación del concepto positivista de "peligrosidad social" sustanciaría lo que determinados juristas denominan como "fraude de las etiquetas" en el circuito penal español en el siglo XX. Este proceso afectó singularmente a la población gitana debido al éxito de la explicación étnica de algunos tipos de criminalidad. Este trabajo, a partir de la exploración de los fondos documentales sobre la "cuestión gitana" custodiados en el Archivo General del Ministerio del Interior, tiene un doble objetivo:

*Este trabajo avanza resultados de una investigación financiada por el proyecto de investigación "Historia de los Gitanos: exclusión, estereotipos, ciudadanía" respaldado por el Plan Nacional de Investigación español (HAR2015-64744-P). Además, la redacción del mismo en su fase final se ha visto enriquecida por los enfoques desarrollados, en cuanto al poder de agencia del activismo romaní en la segunda mitad del siglo XX, en el marco del proyecto europeo BESTROM "Beyond Stereotypes: Cultural Exchanges and the Romani Contribution to European Public Spaces" financiado por HERA Joint Research Programme (www.heranet.info) cofinanciado por AoF, NCN, AHRC, AEI and the European Commission a través de Horizon 2020. 
(1) el primero y más general, contribuir a generar conocimiento sobre la problematización pública de la "cuestión gitana" en España, tomando como referencia el circuito disciplinario que, llamativamente pese a la importante presencia del colectivo, no ha recibido la suficiente atención por parte de la historiografía española;

(2) el segundo y más concreto, analizar su tratamiento policial tanto en las diligencias como en la documentación interna producida por las fuerzas y cuerpos de seguridad del Estado durante la primera andadura democrática.

PALABRAS CLAVE: cuestión gitana, targeting policial, anti-gitanismo, España, conflicto étnico

\section{ABSTRACT}

The success of the positivist legal concept of "social dangerousness" would entail practices of what certain jurists called "fraudulent labeling" within the Spanish criminal circuit in the twentieth century. This process had particular negative effects on the Spanish Romani people due to an ethnic explanation of some types of crimes. The purpose of this work, through exploring the files on the "Gypsy question" available at the General Archive of the Ministry of Interior, is twofold: (1) firstly and most general, to produce knowledge about the public discussion of the "gypsy question" in Spain, taking as a reference the disciplinary circuit that, strikingly enough, has been overlook by Spanish historians despite the significant presence of this minority group;

(2) secondly and more concrete, to analyze police views and approaches in inner proceedings as well as in public records produced by the State security forces in the path to democracy.

KEY WORDS: gypsy question, police targeting, anti-gypsyism, Spain, ethnic conflict

\section{PRÁCTICAS DE ESTADO Y CREACIÓN DE MINORÍAS: EL “GITANO” COMO TARGET EN EL CIRCUITO DISCIPLINARIO EN EL SIGLO XX}

El análisis de la "cuestión gitana" o "problema gitano" en el contexto de la España contemporánea representa en gran medida una asignatura pendiente de nuestra historia política. Son pocos los trabajos que se han planteado el estudio de 
actitudes sociales y prácticas de Estado performativas de minorías. ${ }^{2}$ En concreto, no disponemos de una tradición académica que de forma rigurosa y sistemática haya planteado el encaje normativo y social de la etnicidad gitana, o el grado en que las políticas públicas han podido impactar sobre la identidad de esta minoría, entendiendo la militancia de su tejido asociativo como una forma de adaptación social y cultural resiliente a un medio hostil (Barth 2008). ${ }^{3}$ De ahí que, en este marco estatal, eche en falta una reconstrucción histórica de las estrategias de gobernanza racializada, vinculadas a los procesos de construcción ideológica de las categorías sinalagmáticas de ciudadanía y etnicidad operantes desde el siglo $\mathrm{XIX.}^{4}$

Con todo, en los últimos años y al calor de innovadoras propuestas de investigación, que examinan específicamente las relaciones -complejas y ambivalentes- entre la producción cultural de los estereotipos sobre la población gitana y las prácticas de exclusión política, ${ }^{5}$ se ha comenzado a desbrozar un terreno que augura ser fértil para la academia y la sociedad en un triple plano de conocimiento: (1) la generación de identidades desde la etnicidad; (2) los procesos de esterotipización social; y (3) los discursos de exclusión y prácticas para-legales, ${ }^{6}$ sustentadas casi siempre en relatos policiales y judiciales

${ }^{2}$ Con todo, existen excepciones que merecen ser citadas en este apartado: Martínez Martínez (2018, 2014); Gómez Alfaro (2009); Martínez Dihier (2007); y Sánchez Ortega (1976).

${ }^{3}$ Véase la aproximación conceptual que desde el derecho, en términos de "cultural rights" se ha realizado sobre el proceso de construcción política de minorías en Europa. Desde el ámbito del derecho constitucional español, señalamos el tratamiento de la "cuestión gitana" excepciones notables como, por ejemplo, Rey Martínez (2003: 61-109) y Pérez de la Fuente (2013: 155-198).

${ }^{4}$ Un vacío llamativo teniendo en cuenta el pasado colonial español y el innegable interés en sectores progresistas locales por el debate en torno a la etnicidad e identidad nacional como principio sustentador de derechos de ciudadanía en las sociedades emancipadas en América Latina durante el siglo XIX.

${ }^{5}$ Se trata del proyecto ya citado (HAR2015-64744-P), dirigido por la Profesora María Sierra desde la Universidad de Sevilla y, en concreto sobre el tema del estigma del gitano remitimos a sendas aportaciones en los monográficos publicados en las revistas Historia y Política 40 (2018) e Historia Social 93 (2019).

${ }^{6}$ Considero extraordinariamente productivo en este ámbito la aplicación del concepto de para-penalidad, tal y como lo explica Barbero Santos (1980: 180-181), quien señalaba cómo valores e ideas extrajurídicas, prejuicios sociales, situaba a determinados ciudadanos desde la marginalidad, en una suerte de estado para-penal convirtiéndolos en "blanco de la represión policial". 
estigmatizantes. Es en este último plano en el que aquí se explorará el desafío que la transición de un sistema dictatorial a otro democrático representó para determinadas prácticas institucionalizadas de anti-gitanismo en el circuito policial español, traspasando las relaciones entre la sociedad mayoritaria y el colectivo gitano.

En general, desde el siglo XIX, la percepción pública del llamado "problema gitano" halló una vía prioritaria de "solución" o "tratamiento" en el circuito penal. La movilidad del grupo como uno de los carismas atávica y socialmente reconocibles del "gitano" 7 devino en objetivo especial de vigilancia policial en el mundo euro-atlántico. Se trató de un fenómeno operado sobre bases transnacionales que se tradujo en la tipificación penal de la ideación pseudocientífica de un modo de vida étnicamente inclinado al delito, por considerarse refractario a las reglas familiares, sociales y económicas del ciudadano modélico (García Sanz 2018: 115-146). De ese modo la construcción interesada de la etnicidad del "gitano" (Lucassen y Willems 1998: 86-89), por parte de la antropología física y el derecho penal de la marginación positivista, como "sospechosa", "peligrosa" o "indeseable" desde el punto de vista de las regulaciones migratorias (Sutre 2014: 57-73), comportaría un cercenamiento de las garantías procesales para los etiquetados como tales en la mayoría de los países de Europa y América del Norte.

En el contexto propiamente español, por ejemplo, la naturalización penal de ese carisma grupal implicó la conculcación de los principios de presunción de inocencia y de propiedad privada, reconocidos en la constitución de 1876 (Clavero 1997: 31-55; Martín 2009: 861-951). ${ }^{8}$ Una excepción legal en un Estado

\footnotetext{
${ }^{7}$ El término "gitano", entrecomillado, es usado aquí exclusivamente como etiqueta estigmatizante dentro del circuito policial y judicial, y, por tanto, en ningún caso hace referencia a una etnia ni a los integrantes de la misma.

8 Nos referimos a la "Real Orden circular dictando disposiciones para garantizar la compra-venta y el cambio de caballerías", 13/09/1878 Gaceta de Madrid núm. 256, pp 763- 764 y al "Reglamento para la administración y régimen de las reses mostrencas", 25/04/1905 Gaceta de Madrid, núm. 115 p.340. En ellas, se imponía a este colectivo un requisito específico para el ejercicio profesional, dando carta de naturaleza a su condición de target de las funciones de vigilancia de la Guardia Civil en el ámbito rural. Ambos reglamentos eran claramente anticonstitucionales, al situar a este grupo fuera de la aplicación de los artículos 4o y 11o de la Constitución de 1876: (1) “A toda persona se le debe de considerar inocente mientras no se tengan pruebas concluyentes o vehementes indicios de que es culpable"; (2) "no se impondrá jamás la
} 
de derecho que, desde su singularidad nacional, evidenciaría la paradoja que entrañó la apertura democrática de los sistemas liberales europeos desde 1900: más democracia (participación política) no implicó más libertad para todos los ciudadanos. Conforme se ampliaba el derecho al sufragio se recortaban los derechos civiles de determinados colectivos, a los que se asignaba -en base al análisis positivista del individuo, la sociedad y el Estado- una identidad distinta, peligrosa y/o desviada susceptible de punición automática. Así determinadas identidades, patologizadas bio-antropológicamente, serían portadoras de una "ciudadanía de segunda clase", confinada en jurisdicciones excepcionales discriminatorias -anti-constitucionales en la mayoría de los países del continente- y que, por supuesto, no agotaba la rica pluralidad de relaciones interétnicas fuera del marco penal (Illuzzi 2014; Asseo 2007; About 2014).

Con todo, el potencial instrumental para el control social de dicha paradoja legal explicaría la génesis y adaptación de las tipologías de la desviación en sistemas demo-liberales, viéndose reforzados en su arbitrariedad en los regímenes autoritarios que, en los años treinta, sustituirían en Europa a los primeros. Así, por ejemplo en España, durante el régimen republicano se incorporaron teorías legales reformistas deudoras de modelos criminológicos biologicistas, legitimadores jurídicamente de la noción de "peligrosidad social" y, por tanto, de la sanción sin delito (Campos 2009; 2014). La Ley de Vagos y Maleantes (1933) introdujo en el circuito disciplinario tres clases de medidas llamadas "de seguridad" o profilácticas para su aplicación sobre "sujetos" declarados "peligrosos": (1) internamiento en un establecimiento de trabajo; (2) obligación de declarar el domicilio y alejamiento del mismo; y (3) vigilancia durante un período que solía oscilar entre uno y tres años. La complicada redacción de la Ley de Vagos y Maleantes, que contaría con el apoyo inicial de sectores progresistas, asumía "la tarea necesaria de proceder al ordenamiento de un nuevo código penal que responda con la perfección posible a las exigencias de nuestra época"9 estando "inspirada en las más recientes y logradas doctrinas jurídicopenales"10. Dicha ley, cuya aplicación supuso una decepción para sus impulsores legislativos, sobreviviría a la guerra como complemento al código penal de 1944 y sería reformulada como Ley de Peligrosidad y Rehabilitación Social en 1970.

confiscación de bienes, no pudiendo nadie ser privado de lo suyo sino por autoridad competente e indemnización correspondiente".

${ }^{9}$ Decreto autorización presentación del proyecto de ley a las Cortes, 27/04/1933, Gaceta de Madrid, Núm. 17, pp. 650-654.

${ }^{10}$ Circular relativa a la Ley de Vagos y Maleantes, 14/03/ 1934, Gaceta de Madrid, Núm. 73, pp.1981-1983. 
Éstas, junto al reglamento de la Guardia Civil vigente durante el Franquismo, dieron cobertura legal -mediante el estigma- a la represión contra determinado sectores de la sociedad y un grupo étnico durante más de cuarenta años (García Sanz 2019: 145-165).

Por eso, como pondría de manifiesto, en junio de 1978 a colación de la derogación del reglamento franquista de la Guardia Civil, el entonces diputado de la UCD y activista gitano, Juan de Dios Ramírez Heredia, la nueva agenda política democrática debía atender a "toda una trayectoria de persecución y de discriminación abierta en contra de la población gitana". ${ }^{11}$ Una trayectoria represiva basada en el prejuicio, que había demostrado una enérgica capacidad de resistencia en el tiempo y accidentalismo respecto a la naturaleza de los diferentes sistemas políticos y constitucionales. De ahí que determinadas prácticas policiales, influidas por prejuicios que -como recogía la "Convención Internacional sobre Eliminación de todas las formas de Discriminación Racial", ratificada por España- eran científicamente falsos, moralmente condenables y socialmente injustos, representaran un claro desafío al artículo 14 de la Constitución Española de 1978, garante del principio de igualdad ante la ley. ${ }^{12}$ Años más tarde el artículo 5 1.b de la Ley Orgánica 2/86 reforzaría el principio de supeditación constitucional en ese punto de la acción de las Fuerzas y Cuerpos de Seguridad del Estado, para garantizar un desempeño de sus funciones -entre otras- "sin discriminación alguna por razón de raza". ${ }^{13}$ Fue precisamente en este contexto en el que se produciría el mayor esfuerzo para la erradicación, no siempre con los resultados deseados, del anti-gitanismo en el lenguaje procesal, con inevitables llamadas de atención a la redacción de los atestados policiales. ${ }^{14}$ Se perseguía evitar correlaciones entre una marca étnica y ciertos delitos como

\footnotetext{
${ }^{11}$ Debate de la "proposición no de ley de la situación legal de la población gitana". De los 286 votos emitidos, la proposición fue aprobada por 285 votos a favor, ninguno en contra y una sola abstención.http://www.congreso.es/public_oficiales/L0/CONG/BOCG/BOC_107.PDF [consultado 2 de mayo de 2019]

12 "Convención Internacional sobre la Eliminación de todas formas de Discriminación Racial", adoptada y abierta a la firma y ratificación por la Asamblea General en su resolución 2106 a (XX) de 21 de diciembre de 1965, que entraría en vigor el 4 de enero de 1969 según su artículo 19.

${ }^{13}$ Disponible en [https://www.boe.es/buscar/act.php?id=BOE-A-1986-6859].

${ }_{14}$ Archivo General del Ministerio del Interior (en adelante, AGMI), Dirección General de la Seguridad del Estado, Signatura 57000, SES 471/13 expediente incoado Madrid 27 de mayo de 1985.
} 
"hurto", "tirón", "atraco", "delito contra la propiedad" o "riña tumultuaria". El binomio "gitanos-drogas" proporcionaría, además, desde los años setenta una versión mutada del estereotipo criminal del "gitano" como enemigo público, con un potente arraigo cultural (San Román 1997: 177). En este sentido, el proyecto de crear una "Brigada Central de Delincuencia Marginal" en 1990, ${ }^{15}$ sobre el que volveremos más adelante, trataría de facilitar un nuevo tipo de relación entre la policía y la comunidad gitana, que desde el conocimiento frente al estereotipo, proporcionase una vía de superación de una historia conflictiva, marcada por la sospecha mutua, y que al mismo tiempo permitiese una cooperación en la lucha contra determinados delitos.

Este es, por tanto, el contexto en el que plantearemos el análisis de las rupturas y continuidades en el proceso de transformación que, en términos de "gubernamentalidad"16 sobre este grupo de población, representó el planteamiento más técnico de problemáticas sociales naturalizadas a través de viejos perfiles penales. Para ello, nos serviremos de ejemplos concretos extraídos de los diarios de sesiones del Congreso y el Senado, documentos técnicos del Ministerio del Interior, correspondencia con asociaciones $y$ fuentes hemoragráficas. ${ }^{17}$ Como trataremos de ilustrar en adelante, durante la primera andadura democrática, la imposición en el lenguaje público de términos como "minorías" y/o "marginados" para referirse a los antiguos tipos de la criminología positivista del "delincuente", como en el caso del "gitano", no implicaría renunciar a la noción de "peligrosidad". Un extremo que también condicionaría

${ }^{15}$ AGMI, Dirección General de la Policía, Caja 41321.

${ }_{16}$ El empleo del neologismo "gubernamentalidad", deudor de la "biopolítica" foucaultiana, podría resultar problemático por dos razones: la primera por el carácter controvertido de la "apropiación" del marco foucaultiano y de sus diferentes lecturas y la segunda, por el propio debate en España sobre la naturaleza racializada de las formas de control sobre este grupo de población. Con todo, como se ha señalado en anteriores trabajos (Carolina García Sanz 2018; 2019), pese a las posibles reservas u objeciones que puedan hacerse al enfoque, éste resulta muy productivo para el estudio de la racionalidad del poder detrás de la aplicación de medidas represivas ideadas como solución a la "cuestión gitana" a nivel supranacional y estatal.

${ }^{17}$ Algunos casos de estudio referenciales para este trabajo ya fueron presentados y discutidos en el foro interdisciplinar "Los Contornos del Control" (20 y 21 mayo de 2019), que se celebró en la Universidad de Barcelona, organizado por el Departamento de Geografía y Sociología de la Universidad de Lleida y la revista GeoCrítica, y cuyos resultados se publicarán en un libro colectivo editado por Icaria. 
las políticas "de integración" social que se propondrían subsidiariamente con la creación y puesta en marcha de la "Comisión Interministerial para el estudio de los problemas que afectaban a la Comunidad Gitana” (Real Decreto 250/79). ${ }^{18}$

\section{HACIA UN NUEVO ENFOQUE DE LA CUESTIÓN: EUROPA Y LA DEMOCRACIA}

Desde finales de la década de los años sesenta, el tratamiento de la "cuestión gitana" contribuiría a replantear el estatus de la ciudadanía en Europa y a apostar por un derecho anti-discriminatorio en el marco de la Unión Europea (directiva europea 2000/43/CE sobre igualdad racial o étnica). Un desafío que, para el colectivo que nos ocupa, sigue vigente si consideramos la gitanofobia como la "última forma aceptable de racismo" en la actualidad (MacGarry 2017). De hecho, la condena al racismo como ideología pública y de las políticas de asimilación coactiva sobre los grupos romaníes, se halló presente en distintas reuniones en el marco del Consejo de Europa desde 1969. Resulta lógico, por otra parte, pensar que esos planteamientos -en los que intervino también el activismo de los gitanos españoles- convergerían en el proceso español de adaptación de "gubernamentalidad" durante el Tardofranquismo y la Transición. Durante la década de los sesenta no sólo se consolidaría en España la jurisdicción especial de Vagos y Maleantes para reprimir al "gitano" como enemigo interno, también comenzó a operarse un cambio de sensibilidad en el que tuvo un papel muy importante la doctrina social de la Iglesia, con el encuentro entre Pablo VI y la comunidad gitana en Pomezia (1965). Con todo, la posición de la Iglesia que naturalmente habría de tener gran impacto en un país como España, a mi modo de ver, no fue un fenómeno significativamente permeable sobre el circuito disciplinario. La vía penal continuó siendo la preferente para tratar la "cuestión social” importada y asumida ya por el lenguaje administrativo (García Sanz 2019: 145-165).

En este nuevo espacio que se abre en la década de los sesenta, resulta interesante -por ejemplo- traer aquí las informaciones transmitidas en 1969 por el cónsul general de España en Estrasburgo al Ministerio de Asuntos Exteriores sobre la

\footnotetext{
${ }^{18}$ No abordaremos aquí, por exceder los límites del presente trabajo circunscrito al marco de las fuerzas de orden público, los procesos paralelos de creación de la comisión interministerial con grupos de trabajo con competencias en Sanidad y Servicios Sociales, Trabajo y Formación Profesional, Vivienda, Educación y Cultura y Asuntos Generales y, posteriormente, de la unidad administrativa Programa de Desarrollo Gitano en 1989 (Proposición no de Ley 3/10/1985) para fomentar el desarrollo social y de los estándares de bienestar de la comunidad gitana.
} 
celebración de las reuniones del Comité Internacional Gitano y sus contactos con los representantes de la Asamblea en aquella ciudad. La delegación de la comunidad gitana que asistiría a la reunión del 17 de enero, representaba a asociaciones de catorce países. Según recogía la primera edición de Romano Drom, el órgano de expresión del Gypsy Council británico, además de las "200 páginas de información y quejas" recopiladas por la comunidad en distintos estados se acompañaba material gráfico como testimonio de los problemas habitacionales, de desahucios y brutalidad policial a los que tenía que enfrentarse el colectivo en Reino Unido. ${ }^{19}$ Como resultado de esas iniciativas, se aprobaría la resolución 563 del Consejo de Europa en septiembre de ese mismo año, con la recomendación a la Sección de Asuntos Sociales de dicho Organismo de "que se preocupara de la suerte de los casi dos millones de gitanos" que vivían en el continente (recomendación 563, informe de Daniel Wiklund; una visión negativa sobre el impacto de las mismas en Acton 1974: 178-183; como contraste Liégeois 2013).

En la agenda de la reunión mantenida en Estrasburgo ocupó un lugar destacado la regulación del ejercicio de actividades ambulantes y del régimen administrativo, y no penal, aplicable a las personas sin domicilio fijo en distintos estados, discutiéndose además sobre la etnicidad y la terminología empleada para referirse a este grupo de población (las respectivas legislaciones francesa, inglesa y holandesa adquirieron protagonismo en el debate). Precisamente, el cónsul general español informaba a sus superiores que la problemática de los gitanos españoles -y así lo recogía uno de los documentos de trabajo- era distinta a la de otras poblaciones en el resto del continente ("Manouches" o "Sinties" y "Cíngaros Romsor") porque en España "son sedentarios y es difícil para un extranjero distinguirlos de la población en el seno de la cual viven". ${ }^{20}$ De ahí que se diferenciaran de otros casos en los que "a escala nacional, piden que se les preste una mayor atención por parte de las autoridades al margen de todo paternalismo y más en consonancia con su vocación de trashumantes". ${ }^{21}$ Aquella afirmación entraría en contradicción más adelante con las tesis de algunos de los documentos técnicos de la administración española, en el que la imaginación colectiva sobre un determinado modo de vida gitano permearía la redacción de los mismos.

${ }^{19}$ Romano Drom, 1 junio 1969, p.4

20 "Informe sobre la situación de los gitanos y de otros nómadas en Europa", Asamblea Consultiva del Consejo de Europa, 18 de septiembre de 1969, Doc.2629., p.6, Copia traducida, Ministerio del Interior, Secretaria General Técnica, AGMI, expediente o⒎ ${ }^{21}$ Ibid. 
A la resolución europea de 1969 le siguieron varias acciones durante los años setenta, que se concretaron en un texto adoptado por el Comité de Ministros del Consejo de Europa y más tarde en los ochenta por las iniciativas de la conferencia de poderes locales y regionales (Liégeois 2013: 34-35). En particular, nos interesa destacar las reuniones en Estrasburgo del "Comité de Expertos sobre los nómadas" (la lucha contra los "prejuicios sociales y prácticas discriminatorias" también fueron incluidas en la Resolución (75/13) adoptada por el Comité de Ministros el 22 de mayo de 1975). La "problemática gitana" era abordada en tres planos distintos: "peligrosidad" o "seguridad", "integración" y "discriminación social”. A la reunión de diciembre de 1979 asistiría, como delegado español, el comisario de policía Juan Zamora Moreno (adscrito a la Comisaría General de Documentación). Éste sostuvo que en España "no existía discriminación por parte de la autoridad, de las leyes y de la misma sociedad, sino que la discriminación que pudiera existir nacía de ellos mismos a causa de su cultura, forma de vida, educación...”. ${ }^{22}$ El comisario, además, iniciaba su intervención manifestando que "al hablar de España había que referirse a la problemática gitana, más que al nomadismo". ${ }^{23} \mathrm{Si}$ bien, uno de los principales desafíos para el sistema, tal y como demostraba el llamado "Libro Blanco" de los gitanos (Estudio Sociológico: los gitanos españoles 1978)-resultado de un trabajo desarrollado por el Instituto de Sociología Aplicada de Madrid- venía siendo la inscripción de este grupo de población en el registro civil debido a la "especial idiosincrasia del colectivismo" y "modo de vida nómada". La comunidad gitana se mostraba "refractaria" al Documento Nacional de Identidad y el Libro de Familia. ${ }^{24}$ Los gitanos -se apuntaba- desconfiaban del Estado en general y de las fuerzas del orden en particular. Y ésta era una "problemática" que no sólo afectaba a España. De ahí que la mejora de la relación entre la policía y las minorías en general, no sólo el colectivo gitano, generara una serie de informes técnicos presentados ante el Consejo de Europa entre 1981 y 1982. Con ellos se intentaba promover "un

22 "Informe sobre las reuniones del comité de expertos referente a los nómadas que tuvieron lugar en el Palacio de Europa de Estrasburgo los días 12, 13 y 14 de Diciembre de 1979”, Dirección General Política Interior, AGMI, expediente oo20.

${ }^{23}$ Ibid.

${ }^{24}$ El Director Nacional de Apostolado Gitano al Director Nacional de Política Interior (Servicio Población. Secretaría General), Madrid 18 de mayo de 1979, AGMI, expediente nํ․ 
intercambio de experiencias prácticas, actividades, dificultades... etc.," a nivel supraestatal. ${ }^{25}$

Es en este contexto en el que, a mi juicio, se observa más claramente el tránsito de la penalización a la problematización social de la "cuestión gitana" a través de la documentación interna de los departamentos que, durante décadas, habían sido competentes casi en exclusiva de la "vigilancia" y "tratamiento" de la misma. De ahí que, en la década de los años ochenta, se realizara un esfuerzo de actualización de sensibilidades en el seno del Ministerio del Interior que, sin embargo, no siempre fue considerado suficiente por el tejido asociativo del colectivo. De hecho, proliferarían las denuncias de discriminación, abuso de autoridad y brutalidad policial.

Nos parece interesante rescatar aquí la intervención parlamentaria del diputado gitano Juan de Dios Ramírez Heredia durante la primera legislatura, en relación a la denuncia realizada contra un cabo de la Guardia Civil en San Javier (Murcia), y su interlocución con el ministro competente en la Comisión de Interior de 3 de diciembre de 1980. ${ }^{26}$ Ramírez Heredia trasladaba a sede parlamentaria un "hecho triste, grave" "que no ha sido ciertamente, hecho aislado durante los últimos cuarenta o cien últimos años, sino que lamentablemente se inscribe en la historia de marginación y persecución permanente". ${ }^{27}$ La gravedad del caso para el diputado socialista residía en el empleo de la violencia física y verbal y en que involucrase a un miembro de la Guardia Civil:28

Los gitanos somos un pueblo que normalmente tiene miedo de todo y casi a todos, fundamentalmente hemos tenido miedo y seguimos teniendo miedo a las Fuerzas del Orden Público y de una manera especialísima a la Guardia Civil (...) En este caso concreto, habiendo llegado a la democracia este país, la defensa de las libertades públicas, el derecho de cada ciudadano a manifestarse tal como es, implicaba para nosotros una esperanza en que ese malentendido entre gitanos y Guardia civiles, iba a terminar de una vez por todas, que la cooperación y colaboración sería posible entre todos (...)

25 Véase el Informe Holandés de Bienestar, Sanidad Pública y cultura W.V:C y relación entre la seguridad nacional y las minorías" en AGMI, expediente s/n "Legislación. Informes. Situación de España sobre adhesión a la Convención Internacional sobre eliminación formas de discriminación racial”.

${ }^{26}$ Los hechos ocurrieron en junio de ese mismo año.

27 Debate de la Comisión Parlamentaria de Interior, 3 de diciembre de 1980, Dirección General de Política Interior, expediente n³5, AGMI.

${ }^{28}$ Ibid. 
Pese al tono conciliador con el que Ramírez Heredia iniciaba su contundente alegato contra un abuso de autoridad, en el que además de la violencia física se habría vejado verbalmente al colectivo gitano, el ministro del Interior de la UCD, Juan José Rosón, ofreció una versión alternativa de los hechos relatados por el diputado. Pese a la decepción por la respuesta de Rosón que, para Ramírez Heredia, era una muestra de "la ceguera por parte de los responsables del Ministerio del Interior", éste agradecería la declaración de intenciones del mismo para resolver esa "polémica entre gitanos y Guardia civil, Guardia civil y gitanos". 29

La Asociación Nacional Presencia Gitana, a través de su presidente, Manuel Martín Ramírez, también sería muy activa en su correspondencia con el Ministerio del Interior y, en concreto, con la Dirección General de la Policía Nacional denunciando abusos policiales. ${ }^{30}$ Pero también desde dicha organización se reconocía el cambio positivo que, con la llegada de la democracia, se estaba produciendo en el trato recibido por el colectivo. En junio de 1984 en relación a un secuestro de un menor en Sevilla, tras la intervención del Grupo IV de la Brigada Regional, Martín Ramírez destacaría el servicio prestado a la comunidad gitana "en la nueva hora de España", demostrando la falsedad "de los mitos mendaces, encontrados en la opinión pública, según los cuales "los gitanos roban niños". ${ }^{31}$ Y por otro, apreciaba el trato informativo en las notas de prensa con la omisión de la condición étnica de los implicados: ${ }^{32}$

Parecen haber encontrado Uds. Un punto de equilibrio, donde el derecho de igualdad no sufre la agresión de la desinformación, cuando no la agresión de la frivolidad, de la tentación aceptada del pintoresquismo folklórico o de las calificaciones generalizadoras discriminantes.

Que la Policía actúe, por fin, como agente del cambio social que nuestra Patria común precisa, nos congratula tanto más cuanto que, como señalara el viejo proverbio latino, leges, sine moribus, vane proficiunt. La comunidad gitana tiene derecho a saber y a sentir que la justicia también es justicia para ella, dejando de ser el chivo expiatorio, eternamente sospechoso por la única razón de

\footnotetext{
${ }^{29}$ Ibid.

${ }^{30}$ Las comunicaciones entre Presencia Gitana y la Dirección General de Política Interior está documentada y archivada en el AGMI.

${ }^{31}$ Dirección General de Política Interior, SIGNT.57000 Ibid.

32 Ibid.
} 
poseer un rasgo identificador de cuya diferencia se siente orgullosa: estar constituida por españoles gitanos.

Casi un año después, en mayo de 1985, el Director de la Seguridad del Estado, el socialista Julián Sancristóbal, continuaba incidiendo sobre la supresión de la marca étnica de "gitano" en los informes sobre actos delictivos. ${ }^{33}$ En este sentido, las "adjetivaciones que afectan a la integridad de la raza gitana" en los atestados policiales fue una de las cuestiones sobre las que se realizaron más llamadas de atención tanto públicamente como a nivel interno.

Pero no sólo se trataba de modificar el lenguaje sino también y sobre todo determinadas prácticas. Este segundo aspecto ofrecía aún más dificultades que el primero. Así, por ejemplo en marzo de 1984, el Gobernador Civil de Teruel trasladaba al Subsecretario de Interior el dilema que observaba entre el cumplimiento de las garantías constitucionales y la seguridad pública, en relación a la grave reyerta que, en diciembre del año anterior, había tenido lugar en el barrio Pomecia de Teruel, "ocupado únicamente por miembros de esta comunidad": 34

como medida cautelar y en base al artículo 10 de la Ley de Orden Público, acordé la ocupación temporal de todas las armas de que son titulares los miembros de la comunidad gitana, en número aproximado de 30, por entender que existían fundados indicios de peligro (...) uno de los titulares de las armas ocupadas ha solicitado su devolución (...) está la necesidad de observancia de los principios constitucionales de igualdad ante la Ley, que impide la adopción de actuaciones restrictivas por la simple pertenencia a una comunidad étnica concreta con carácter general, y el de la legalidad, que obliga a limitar las medidas excepcionales en cuanto a sus efectos y su duración, al mínimo (...) Más problema va a plantear la devolución de las armas al resto de la población gitana que permanece en Teruel, puesto que sin existir indicios próximos de conflicto, es sobradamente conocido que dentro de estos grupos los motivos pueden permanecer larvados largo tiempo, y aparecer en el momento menos pensado (...) demoraré prudencialmente esta segunda fase del proceso de devolución.

33 Dirección General de la Seguridad del Estado, Signatura 57000, SES 471/13 expediente incoado Madrid 27 de mayo de 1985, AGMI.

${ }^{34}$ El Gobernador Civil de Teruel 27 de marzo de 1984 al Subsecretario de Interior. Dirección General de Política Interior SIGNT. 12973, AGMI. 
En relación a la constitucionalidad de determinadas medidas cautelares o preventivas, la sentencia del Tribunal Supremo de 13 de enero de 1988, condenando al Ayuntamiento de Madrid por haber conculcado "el derecho de igualdad reconocido en la Constitución", con un dispositivo de vigilancia especial sobre el poblado gitano de Vicálvaro en 1984, pondría nuevamente el foco de atención pública (Calvo Buezas 1990: 27). Habría, por tanto, que continuar trabajando para reforzar la constitucionalidad de la acción de los cuerpos de seguridad en el desempeño de sus funciones "sin discriminación alguna por razón de raza". ${ }^{35}$

En 1990 el proyecto de crear una "Brigada Central de Delincuencia Marginal", en el Servicio Central de la Policía Judicial, buscaría responder a la necesidad de diálogo y cooperación por el colectivo, que venía siendo formulada como una aspiración desde la primera legislatura democrática. En el acta de la reunión mantenida entre los mandos policiales y nueve "hombres de respeto" gitanos el 27 de marzo de 1990 en el Salón de Actos de la Dirección General de la Policía de Madrid se señalaba como principal propósito el "acercamiento entre la Institución Policial y el colectivo de Respetables gitanos". ${ }^{36}$ De ese modo se crearía un clima propicio para "dar cabida a cuantas demandas y quejas desee trasladar el indicado colectivo a la Institución Policial”, constituyendo las más importantes: ${ }^{37}$ (1) una oficina de atención al mundo gitano "con policías que entiendan y quieran a este colectivo"; (2) soluciones a los problemas generados por la venta ambulante; (3) "la legalización documental"; (4) acabar con la discriminación; y (5) compartir esta experiencia "a través de INTERPOL, para que por parte de la Policía Internacional, haya un acercamiento al mundo gitano".

Las tareas de ese grupo también incluían abrir canales de diálogo con las asociaciones gitanas "legalmente constituidas" y la "Iglesia Evangélica de Filadelfia" así como la interlocución ante ayuntamientos y comunidades autónomas "en las justas reivindicaciones del colectivo: puestos de venta ambulante, mercadillos, realojos, etc.”.

\footnotetext{
35 https://www.boe.es/buscar/act.php?id=BOE-A-1986-6859. [Consulta 3 de mayo de 2019]

${ }^{36}$ AGMI, Dirección General de la Policía, Caja 41321.

${ }^{37}$ Ibid.
} 
Si bien, no debe pasar desapercibido que la policía a través de esa experiencia con el colectivo gitano perseguía, además, avanzar en la aproximación hacia otros grupos de "conducta incomprensible" en su tratamiento policial: ${ }^{38}$

Dicha Brigada ha de atender en un principio a aquellos grupos de conductas claramente delictivas, que en la actualidad están causando gran alarma social y contra la que se están movilizando los ciudadanos en demanda de mayor seguridad urbana (venta de droga en barrios y por individuos de raza gitana), para ampliarse en un futuro próximo hacia el conocimiento y tratamiento de actitudes, subculturas o contraculturas y movimientos que presentan jóvenes atípicos: plataformas libertarias juveniles, xenofobias juveniles, objetores de conciencia, okupas, vándalos (hoollegans, skin-heads, italo-houses, rappers, etc...) que se están haciendo presentes en la sociedad, en algunos casos incomprensibles en su tratamiento policial por su total desconocimiento.

En realidad, más allá de la retórica del wishful thinking, en aquel documento se reproducían viejos esquemas mentales sobre el "gitano", con la transposición de la categoría "criminal" a la de "marginal". La preocupación por la "marginalidad" aparecía como una vía para la reformulación, con mejor inserción en el régimen constitucional del 78, del concepto positivista de "peligrosidad" bajo el más aceptable o políticamente correcto de "alarma social". En esta clave podría leerse, por ejemplo, la polémica provocada en octubre de 1991 por las declaraciones del Secretario de Estado para la Seguridad, el socialista Rafael Vera, ante la Comisión Mixta sobre el Estudio de la Droga en el Senado, sosteniendo que "el 70\% del tráfico de heroína está en manos de los gitanos". Las palabras de Vera fueron censuradas airadamente por el asociacionismo por las acusaciones vertidas "contra colectivos que no tienen defensa, mientras que en cambio, no se investigan las redes de distribución y financiación de la droga". ${ }^{39}$ Aquellas declaraciones del responsable de Interior se produjeron, además, en un clima de elevada tensión por la movilización vecinal en el barrio madrileño de Villaverde. Unas dos mil personas llegarían a enfrentarse a la policía para paralizar las obras con objeto de dar una solución habitacional a ochenta y ocho familias gitanas procedentes del distrito de Vicálvaro. ${ }^{40}$

\footnotetext{
${ }^{38}$ Ibid.

39 "Dossier de prensa: gitanos y drogas" (25/10/ 1991) caja 41322, AGMI.

40 "Las drogas como telón de fondo. Los vecinos de Villaverde desafiaron a la policía".

El País, Madrid, 4 de octubre. Disponible en
} 


\section{A MODO DE EPÍLOGO: POLICÍAS Y PAYOS EN LA ENCRUCIJADA}

En una de las ponencias presentadas durante el encuentro estatal celebrado en Zaragoza sobre el Programa de Desarrollo Gitano de mayo 1993, se establecían cuatro fases en "la evolución del asociacionismo gitano": una primera (19401963) de "ninguneo étnico" y represión"; una segunda (1964-1976) marcada por la Iglesia católica "benefaciente"; una tercera (1977-1984) de consolidación democrática y de "conflictos"; y una última de "institucionalización del asociacionismo" y "colaboración administrativa" (Calvo Buezas 1993). ${ }^{41}$ Pero sucesos como los de Villaverde, con los que concluíamos la sección anterior, demostrarían la ausencia de solución de continuidad entre esas dos últimas etapas, al menos en cuanto al desafío de las relaciones interétnicas. En concreto el proceso de condena pública a la estigmatización racista operado, durante la década de los años ochenta, en el circuito disciplinario junto a los intentos de establecer nuevas dinámicas en las relaciones entre la policía democrática y este colectivo minoritario de ciudadanos españoles, coincidiría en el tiempo con una intensificación de acciones colectivas de anti-gitanismo.

Entre 1976 y 1995 se publicaron en El País noticias sobre más de 213 manifestaciones de esa naturaleza, alcanzando algunas de ellas por la gravedad de sus implicaciones una inmensa cobertura mediática y repercusión política (Río 2019: 200). Entre los casos más controvertidos políticamente habría que señalar la polémica orden de expulsión de los gitanos de Hernani aprobada el 8 julio de 1980 en el pleno municipal. Con el respaldo de los concejales de Herri Batasuna, Partido Nacionalista Vasco y Euskadiko Ezkerra, y la oposición de los socialistas por ir en contra del Estatuto de Autonomía y de la Constitución, sería justificada públicamente por "respetar la voluntad del pueblo" al tratarse de una moción popular ante los problemas de salubridad y "supuestos robos que se achacan a los gitanos". ${ }^{42}$ Un concejal de HB explicaba ante un medio de comunicación de

[https://elpais.com/diario/1991/10/04/madrid/686579062_850215.html] Consultado 19 septiembre 2019.

${ }^{41}$ Tomás Calvo Buezas, ponencia "Evolución de la minoría étnica en España: perspectiva antropológica" I Encuentro Estatal sobre el Programa de Desarrollo Gitano. Zaragoza 5,6 y 7 de mayo 1993. Consultado en AGMI.

42 "Quieren expulsar a los gitanos. El PSOE de Euskadi, contra el Ayuntamiento de Hernani”. Informaciones, Madrid, 14 de julio de 1980. Consultado en el amplio dossier de prensa recopilado sobre este caso en Dirección General de Política Interior, expediente no32, AGMI. 
Madrid que la medida trataba de poner fin a los "graves altercados entre los vecinos y los gitanos", admitiendo "que no siempre han sido culpables los gitanos, pero se ha llegado a una auténtica psicosis en el pueblo" ${ }^{43}$ Con todo, el teniente de alcalde de dicha formación admitía: "hemos tenido que decir que sí, que se vayan. Pero ¿cómo se van a ir? Yo no voy a mandar a los veinte policías municipales que tengo para que los echen". ${ }^{44}$ La movilización tanto del diputado Juan de Dios Ramírez Heredia, de la Asociación de Gitanos de Guipúzcoa y otras asociaciones a nivel estatal, de Max Mazin en nombre de la sección española de B'nai B'rith, organización judía mundial de defensa de los derechos humanos, así como de distintas instancias del Gobierno Civil, terminaron con la suspensión de una medida calificada abiertamente de racista y anticonstitucional. Sin embargo, llamamos la atención en este punto sobre la insistencia en el "corte democrático" de la medida en la que insistían los partidos que la apoyaron, al tratarse de una moción popular.

Pese al rechazo generalizado en los medios de comunicación a la moción adoptada por el pleno del ayuntamiento vasco, lo cierto es que hubo algunas propuestas de emulación en otros puntos de la geografía peninsular al mismo tiempo que la retórica anti-gitana era asumida por determinados ediles y concejales a nivel municipal. Dos años más tarde, en el verano de 1982, el secretario del Ayuntamiento de El Palau d'Angiasola se vio obligado a pedir perdón públicamente en una carta en el diario La Mañana por afirmar que "en España habría que hacer con los gitanos como en Alemania hicieron con los judíos". ${ }^{45}$ En 1984 en una carta abierta a un subsecretario del Ministerio del Interior, éste era interpelado en los siguientes términos: ${ }^{46}$

Estos días en razón de haberse puesto en Primer Plano el Tema-Problema Gitano, es momento para comentar respecto a las Remesas de Gitanos que están y estuvieron estos 2-3 años últimos, Cruzando las Fronteras de Portugal hacia España, como "Juan por su casa". Ellos con toda su carga de Cacharrería, Suciedad, Analfabetismo, ser mendigantes Profesionales, y que "Utilizan" descaradamente a sus hijos en ello, aparte ser fuente de cualquier cosa o vicio (cercanos a la Delincuencia, en casos) por su forma de vivir, dicen son "Raza".

43 "Hernani: hacia la solución final del problema gitano. Teniente de alcalde por HB: "los gitanos aumentaron alarmantemente", El Imparcial, Madrid, 13 de julio de 1980. Ibid.

${ }^{44}$ Ibid.

${ }^{45}$ La Mañana (Lleida), 11 de agosto de 1982, ibid.

46 "Al Señor Sub-Secretario del Ministerio del Interior" 17 octubre de 1984 (un particular) Signatura 11064, AGMI. 
Ello como si no bastase con la recría y abundancia de Gitanos de aquí, "su Gran Error", que les degrada, pues sin tener apenas medios de subsistencia despreocupadamente pasan a tener $6,8,12$, Hijos (....) ¿Bajo qué criterios actúan los Vistas y Jefes de Aduana, ante la entrada de tanta chusma por su Frontera?(...) ¿habrían conseguido entrar estos Gitanos por una Aduana Alemana, Suiza, Inglesa...jjamás!

Los estallidos de violencia anti-gitana se replicaron durante más de una década, alcanzando puntos de especial intensidad a principios de los noventa con la movilización vecinal en barrios de periferias urbanas, como Villaverde en Madrid, o con hechos delictivos tan graves como los de Mancha Real en Jaén, en los que vecinos incendiaron viviendas de familias de etnia gitana "burlando la vigilancia de la Guardia Civil". ${ }^{47}$

Este trabajo no se proponía analizar en perspectiva histórica las acciones colectivas de anti-gitanismo en España. Si bien, podríamos concluir en este último apartado que, atendiendo a la cronología y a la nueva racionalidad del poder democrático (no siempre acompañado por sus prácticas), el tránsito de la penalización a la problematización social de la realidad gitana visibilizaría la fuerza del estigma social, detrás de la construcción cultural de una etnicidad criminal. La lucha contra la criminalidad como asidero de legitimidad popular para justificar la agresión, como excepción al ordenamiento constitucional, dejaba de tener cobertura institucional y complicidades explícitas con las fuerzas del orden, al mismo tiempo que abrazaba ese respaldo "popular". De este modo, los "mapas mentales" estigmatizantes e incriminatorios para la "defensa social" no sólo demostrarían su vigor en democracia sino que, con el desarrollo económico, terminarían proyectándose sobre otras minorías étnicas y grupos migrantes. Una percepción de "peligrosidad", amparada en la "alarma social", que en la actualidad centra el debate político y jurídico sobre el control de los movimientos de población en el primer mundo.

\section{BIBLIOGRAFÍA}

ABOUT, I. (2014): "Unwanted "Gypsies". The Restriction of Cross-Border Mobility and the Stigmatisation of Romani Families in Interwar Western Europe", Quaderni Storici, 49 (2), pp. 499-532.

${ }^{47}$ El País, 13/07/1991, ibid. 
ACTON, T. (1974): Gypsy politics and social change. The development of ethnic ideology and pressure politics among British Gypsies from Victorian reformism to Romany nationalism, London and Boston: Routledge \&Kegan Paul.

ASGG ed. (1990), Estudio Sociológico: los gitanos españoles 1978, Madrid, Asociación Secretariado General Gitano.

ASSEO, H. (2007) : "L'invention des "nomades" en Europe au XXe siècle et la nationalisation impossible des Tsiganes", L'identification des personnes. Genèse d'un travail d'État en G. Noiriel (coord.), Paris, Belin, pp.161-180.

BARBERO SANTOS, M. (1980), Marginación Social y Derecho Represivo, Barcelona, Bosch.

BARTH, W. K. (2008): On Cultural Rights: The Equality of Nations and the Minority Legal Tradition, Leiden, Brill.

CALVO BUEZAS, T.(1990): ¿España racista?: voces payas sobre los gitanos, Madrid, Anthropos Editorial.

CAMPOS, R. (2009): "La clasificación de lo difuso. El concepto de "mala vida" en la literatura criminológica de cambio de siglo", Journal of Spanish Cultural Studies, 10, (4), pp. 399-422.

CAMPOS, R. (2014): "Pobres, anormales y peligrosos en España (1900-1970): De la "mala vida" a la ley de peligrosidad y rehabilitación social", XIII Coloquio Internacional de Geocrítica El control del espacio y los espacios de control Barcelona (5-10 de mayo). Disponible en http://www.ub.edu/geocrit/coloquio2014/Ricardo\%20Campos.pdf.

CLAVERO, B. (1997): "Legislación Universal para los pueblos modernos (18681914)" en La revista jurídica en la cultura contemporánea V. Tau Anzoátegui (ed.), Buenos Aires: Seminario sobre Las Revistas Jurídicas Españolas, pp. 3155 .

GARCÍA SANZ, C. (2018): "Disciplinando al gitano" en el siglo XX: Regulación y para-penalidad en España desde una perspectiva europea", Historia y Política, 40, pp.115-146.

GARCÍA SANZ, C. (2019): "Presuntos Culpables: Un estudio de casos sobre el estigma racial del "gitano" en juzgados franquistas de Vagos y Maleantes", Historia Social, 93, pp.145-165. 
GÓMEZ ALFARO, A. (2009), Legislación histórica española dedicada a los gitanos, Sevilla, Secretaría para la Comunidad Gitana, Consejería para la Igualdad y Bienestar Social.

ILLUZI, J. (2014) : Gypsies in Germany and Italy, 1861-1914. Lives Outside the Law, Basingstoke, Palgrave.

LIÉGEOIS, J. P. (2013): The Council of Europe and Roma: 40 years of activity, Consejo de Europa.

LUCASSEN L., WILLEMS W., COTTAR A. (1998): Gypsies an Other Itinerant Groups. A Socio-Historical Approach, New York, Macmillan Press.

MARTÍN, S. (2009): "Criminalidad politica y peligrosidad social en la España contemporánea (1870-1970)”, Quaderni fiorentini per la storia del pensiero giuridico moderno, 38 (1), pp.861-951.

MARTÍNEZ DHIER, A. (2007): La condición social y jurídica de los gitanos en la legislación histórica española [tesis doctoral inédita], Universidad de Granada.

MARTÍNEZ MARTÍNEZ, M. (2014): Los gitanos y las gitanas de España a mediados del siglo XVIII: el fracaso de un proyecto de "exterminio" (17481765), Almería, Universidad.

MARTÍNEZ MARTÍNEZ, M. (2018): “Clamor y rebeldía. Las mujeres gitanas durante el proyecto de exterminio de 1749”, Historia y Política, 40, pp.25-51.

MCGARRY, A. (2017), Romaphobia: The Last Acceptable Form of Racism, London, Zed Books.

PÉREZ DE LA FUENTE, O. (2013): "Minoría gitana, Derecho penal y teorías republicanas del castigo", Cuadernos electrónicos de Filosofía del Derecho, 27, pp.155-198.

REY MARTÍNEZ, F. (2003): "La prohibición de discriminación racial o étnica en la Unión Europea y en España. El caso de la minoría gitana”, Revista de Derecho Político, 57, pp. 61-109.

RÍO RUIZ, M.A. (2018): “Antigitanismo y cambios en los derechos y condiciones escolares de la infancia gitana en España (1970-1995)”, Historia y Política, no40, pp.179-210.

SAN ROMÁN, T. (1997): La diferencia inquietante. Viejas y nuevas estrategias culturales de los gitanos, Madrid, Siglo XXI. 
SÁNCHEZ ORTEGA, M. H. (1976): Documentación selecta sobre la situación de los gitanos españoles en el siglo XVIII, Madrid, Editora Nacional.

SUTRE, A. (2014): "Are you a Gypsy? L'identification des tsiganes à la frontière amèricane au tournant du XXe siècle. Migrations societe, 152, pp. 57-73.

Recibido: 10 de septiembre de 2019

Aceptado: 15 de octubre de 2019

Carolina García Sanz es Profesora del Departamento de Historia Contemporánea de la Universidad de Sevilla. Su campo de trabajo principal es la Historia Internacional. Es experta en la historia de la Primera Guerra Mundial y editora de la sección sobre España del proyecto colaborativo de la Universidad Libre de Berlín International Encyclopedia of the First World War 1914-1918 on line y coordinadora de la Red Transnacional de Estudios Culturales sobre Conflictos e Identidades. Actualmente está trabajando en la "cuestión gitana" y su planteamiento a nivel internacional, así como en las prácticas de targeting policial y sentencing judicial en el siglo XX. Entre sus publicaciones recientes: (ed.) Shaping Neutrality throughout the First World War(2016); en co-autoría "Neutralist crossroads: Spain and Argentina facing the Great War", First World War Studies (2017); "Disciplinando al Gitano' en el siglo XX: Regulación y parapenalidad en España desde una perspectiva Europea', Historia y Política 40 (2018) y "Presuntos culpables: Un estudio de casos sobre el estigma racial del "gitano" en los juzgados franquistas de Vagos y Maleantes" Historia social 93(2019). 